fecd. The four little cans were presented to goats during a sequence of 4 periods of 20 seconds with breaks of 10 seconds during which the position of cans was modified.

A scale of aceeptability was settled from 4 standard feeds containing a mixture of barley-soya oilmeal (4/1) and 6 p. 100 molasses (Feed M), or 10 p. 100 rapeseed oilmeal (Feed R), or 15 p. 100 lucerne meal (Feed L) or 5 p. 100 animal fat (Feed F).

The palatability value of a feed was the ratio between the average lovel of feed intake and the total amount ingested in all the tests where this feed was tested and noted in a scalc from 0 to 10 . The palatability values of fecds, $M, R, L$ and $F$ were $7.5,6.1,5.4$ and 2.6 respectively.

Five commercial fats (acid or non acid animals fats, oils or mixtures) which could decrease the palatability of concentrates for cows were incorporated into the mixture barley-soya oilmeal and they were tested with standard feeds R, L and F. The acceptability values of feeds containing these commercial fats ranged from 2.8 to -1 . I. In this trial, the palatability of standard feeds was relatively high in comparison with fat added feeds. To give palatability values to fat addled feeds, it was necessary to do a translation in the palatability scale; which explains negative valucs of some feeds. Acid fats were generally less accepted than non acid ones.

So, this cafeteria test might allow to classify feeds according to their palatability for goats in a stable palatability scale which could be completed by testing every new feed.

At the present time, it is necessary to test if cows give the same classification of feeds as goats to discriminate concentrate feeds.

Key words : Concentrate feeds, acceptability, goat, fat, cafeteria, acceptability scale.

\title{
Body conditions of dairy goats in extensive systems of production : method of estimation
}

\author{
P.M. SANTUCCI, O. MAESTRINI
}

Labornaro de Recherches sur le Développement de lelevage

I.N.R.A. - Quartier Grossetti - 20250 Corte

Continuous rccording of performance parameters in three flocks of dairy goats (Corsican breeds) for three consecutive years showed that the flocks were composed of four kinds of animals defined by the kidding interval (K.I.). There are two periods of kidding in the year : october-november and fcbruary-march. The K.I. is twelve months for most females (65 p. 100); it can be cighteen (16 p. 100), twenty four (14 p. 100) or seven months (5 p. 100) in others. These intervals vary from one year to another. The body condition of goats seem to be the main responsible factor for these variations.

The method used for estimating body conditions was based on Russiz.'s results (1959) in ewes. Recording was made on the sternum and the lumbar vertebrac. Using a grading scale from to 0 to 5 we tried to score a fat bulk (importance, thickness) at the lcvel of the stcrnum and a tissue bulk (grease and muscles) on the lumbar (thickness, iceovery).

Otherwise the siudy of 41 slaughtered goats showed a significant comelation $(r=0.62)$ between the weight of sternum and the notation given to animals before slaughier.

Variations in body conditions were similar in all animals during the reproductive cycle : a distinct decrease after kidding and a quick increase in spring-time. But the extent of these variations was significantly different between various kinds of animals as defined above.

The shorter the K.I. (medium score $=2.5$ when K.I. $=7$ months and 3.0 when the 
K.I. $=12$ months) or the longer the suckling period or the higher the milk yield and the higher the lipid mobilization.

We also observed changes in the production of milk fat + protein $(83.0 \mathrm{~g} /$ day for females with K.I. of seven months vs $86.4 \mathrm{~g} /$ day with a K.I. of twelve months).

This work showed the importance of body conditions in goats at mating and its effect on fertility. It also demonstrated the necessity of perfecting for evaluating the reproductive and milk potential of goats in extensive systems of production.

Key words : Extensive system, body condition, kidding period, kidding interval, grading scale, goat.

\title{
Effect of concentrate allowance on ad libitum hay consumption by lactating British Saanen goats
}

\author{
A. MOWLEM, J.D. OLDHAM *, S. NASH \\ Animal and Grassland Research Institute. \\ Shinfield, Reading, Berkshire, RG2 9AQ, England \\ * The East of Scotland College of Agriculture, Bush Estate, Penicuik, \\ Midlothian, EH26 OP11, Scotland
}

Twenty seven British Saanen goats were offered a controlled ration during the last 12 weeks of pregnancy. The daily allowance was $1.5 \mathrm{~kg}$ grass hay $(8.0 \mathrm{p} .100 \mathrm{CP})$ plus $150 \mathrm{~g}$ of dairy concentrate ( 17 p. $100 \mathrm{CP})$ until 4 weeks before predicted kidding, then concentrate was increased to $450 \mathrm{~g}$ until kidding. At kidding the goats were allocated to three treatments of low $(0.7 \mathrm{~kg})$ medium $(1.2 \mathrm{~kg})$ or high $(1.7 \mathrm{~kg})$ daily concentrate allowance. The concentrate allowance was gradually increased so that all goats received their full allowance by wcek 3 of lactation and was then held constant until week 11. Hay was available ad libitum throughout the lactation period. Milk yield, milk fat, live weight and hay and concentrate intake were monitored throughout the trial. In a similar way to what has previously been observed in cattle, the hay intake was substantially reduced $(669 \mathrm{~g})$ in the group offered a high level of concentrate $(1389 \mathrm{~g})$ and there was only a slight reduction $(1102 \mathrm{~g})$ in the medium group (1000 g concentrate) compared with the low group (1 $222 \mathrm{~g}$ hay/593 $\mathrm{g}$ concentrate). The calculated replacement rate of hay dry matter (DM) intake by concentrate DM intake was 0.25 between low and medium but 1.0 between the medium and high concentrate allowance. Both milk yields $(2.69,2.94,3.21 \mathrm{~kg} /$ day $)$ and calculated Metabolisable Energy (ME) (17, 21, $23 \mathrm{MJ} /$ day) intake increased according to a pattern of «diminishing return » as concentrate allowance increased. The milk fat concentration was generally low at the time of the trial and there was little effect on concentrate allowance. The results confirm principles established with dairy cows that high rates of concentrate allowance will reduce forage consumption and utilization. The economic consequences will depend on the concentrate milk price ratio, but in general, excessive concentrate allowance will not optimise economic efficiency of goat milk production.

Key words : Goat, concentrate, forage, replacement. 